ARTÍCULO

\title{
LOS SOLDADOS DE LEVA DURANTE LA GUERRA DE CASTAS FILIACIÓN Y COMPOSICIÓN SOCIAL MEDIANTE SUS JUICIOS DE AMPARO, 1875-1903*
}

\author{
LEVY SOLDIERS DURING THE CASTE WAR \\ RECORD CARDS AND SOCIAL COMPOSITION AS REGISTERED IN AMPARO \\ PROCEEDINGS, 1875-1903
}

\author{
Pascale Villegas \\ Universidad Autónoma de Campeche \\ Centro de Investigaciones Históricas y Sociales \\ pmvilleg@uacam.mx
}

\begin{abstract}
Resumen
Partiendo de los juicios de amparo por reclutamiento forzoso en el servicio de las armas interpuestos en el Tribunal de Campeche entre 1875 y 1903, este trabajo tiene como objetivo analizar los procedimientos judiciales y las sentencias para determinar quiénes fueron esos soldados, su origen, cómo fueron reclutados y cómo recurrieron a este medio de defensa legal para evitar formar parte de las fuerzas armadas del ejército mexicano presente en los diferentes puestos militares establecidos en la península de Yucatán para combatir a los mayas rebeldes en plena Guerra de Castas.
\end{abstract}

Palabras clave: leva; ejército federal; Campeche; amparo; Guerra de Castas.

\begin{abstract}
The present work is aimed to analyze the amparo proceedings invoked by recruits against forced military recruitment in the Court of Campeche between 1875 and 1903. Judicial proceedings and sentences are analyzed to determine who these soldiers were, their own origins, recruitment ways, and how they invoked this legal recourse to avoiding recruitment by the Mexican Army, at that time deployed through several military posts along the Yucatan Peninsula to fight rebel Maya Indians during the Caste War.
\end{abstract}

Keywords: levy; federal army; Campeche; amparo; Caste War.

Información del artículo

Recibido: 30 de septiembre de 2019.

Aceptado: 12 de noviembre de 2019.

DOI: $10.22201 /$ iih.24485004e.2020.59.70965

* Un especial agradecimiento al licenciado Jorge A. Solís López y a la licenciada Berenice Rojas Flores por la primera lectura y comentarios, además a la licenciada Rossana Ucán Chan, del Archivo General del Estado de Campeche, y al licenciado Juan Manuel Huchin Uc de la Casa de la Cultura Jurídica de Campeche por sus atenciones. 
Durante la época colonial y a lo largo del siglo XIX, el reclutamiento forzoso en el ejército también conocido con el término de leva fue la manera más rápida y poco costosa para engrosar las filas de soldados durante un conflicto bélico, la cual conllevó un alto índice de deserciones. Durante los primeros cincuenta años del México independiente, la vagancia y el desempleo eran motivos suficientes para la filiación de varones en la edad productiva en un ejército todavía poco profesional y poco disciplinado a pesar de las constantes denuncias de ser un procedimiento impopular, nocivo, degradante y dañino en los periódicos, memorias y literatura de la época. ${ }^{1}$ Para algunos, la leva era el mejor método para limpiar la sociedad de criminales y vagabundos que abundaban en los caminos y en las calles de la capital según la circular de agosto $1838,{ }^{2}$ aunque armar y vestir de uniforme a criminales carentes de honor no podía ser más perjudicial e inconveniente ni para la patria y ni para los ciudadanos. ${ }^{3}$

El general José María Tornel, entonces ministro de Guerra y Marina, dictó una serie de decretos ${ }^{4}$ en un intento de mejorar la organización, la

${ }^{1}$ El Cosmopolita denunció varias veces esta práctica cuyo denominador común era el maltrato de esos hombres "forzados, conducidos en cuerdas, desnudos, hambrientos, acosados de sed", 16 de diciembre 1837, 2; 8 diciembre 1838, 3; 23 enero 1839, 4. Las críticas de la época en varios medios fueron desempolvadas por Claudia Ceja Andrade, "Amanecer paisanos, dormir soldados... El reclutamiento forzoso en la ciudad de México, 1824-1858”, Estudios de Historia Moderna y Contemporánea de México, n. 55 (2018): 3-40, http://dx.doi. org/10.22201/iih.24485004e.2018.55.63296.

${ }^{2}$ En El Cosmopolita del 2 de junio de 1838, 5, la leva y el sorteo eran las formas "más preciosas y a propósito para limpiar las sociedades de hombres dañinos".

${ }^{3}$ Carta del síndico segundo del H. ayuntamiento [de la ciudad de México], Juan Rodríguez de San Miguel, al Presidente de la República en contra de la Circular, 24 de agosto de 1838 publicada en El Cosmopolita, 26 de septiembre de 1838, 1-2.

${ }^{4}$ Dentro de la ley del 13 de junio de 1838, llamada Novísimas disposiciones sobre materia militar o sea sobre organización y aumento del ejército, existe una serie de veinte decretos y reglamentos expedidos entre septiembre de 1838 y octubre de 1839; citamos entre otros la Ley penal para los desertores, viciosos y faltistas del ejército nacional megicano [sic], 29 de diciembre de 1838, en Juan M. Rodríguez de S. Miguel, Pandectas hispano-megicanas o sea Código general comprensivo de las leyes generales, útiles y vías, v. 2 (México: Impreso en la oficina de Mariano Galván Rivera, 1840), 82-87; Decreto para reemplazar las bajas del ejército megicano [sic] por sorteo general, 26 de enero de 1839, en Rodríguez de S. Miguel, Pandectas hispano-megicanas..., v. 2, 128-134; Decreto para organizar los cuerpos de infantería y caballería del ejército nacional megicano [sic], 16 de marzo de 1839, en Rodríguez de S. Miguel, Pandectas hispano-megicanas..., v. 2, 95-98; Decreto sobre la enseñanza primaria del ejército de la república megicana [sic], 24 de junio de 1839, en Rodríguez de S. Miguel, Pandectas hispano-megicanas..., v. 2, 103-105; Decreto sobre los uniformes de los regimientos de Infantería y Caballería permanente, 10 de julio de 1839, en Rodríguez 
eficiencia y la educación del ejército mexicano basado en el aumento del tamaño de los efectivos procedentes de toda la República, la alfabetización de sus soldados y la inculcación del respeto ante las instituciones gubernamentales y las leyes; pero, además del sorteo y del voluntariado, las redadas sorpresivas seguían siendo la forma de enganchar a carpinteros, sastres, herreros, albañiles, zapateros, panaderos, una costumbre generalizada a lo largo del siglo XIX como veremos a continuación en el caso de Yucatán.

Para las décadas de 1830 y 1840, en la península yucateca, varios habían sido los conflictos que opusieron las tropas del gobierno central contra las de Yucatán, conformadas principalmente por mayas reclutados a la fuerza o por voluntarios indígenas a quienes se les otorgaba el título de hidalgo al término del conflicto. Aunque oficialmente el artículo 4 de la convención concluida en diciembre de 1841 entre el gobierno mexicano y el de Yucatán estipulaba que la península ya no iba a ser tierras de levas, ni de sorteos "ni otros medios que el de enganche", 5 durante el conflicto armado de 1842 en el cual se opusieron de nuevo las tropas mexicanas y las yucatecas, el cónsul francés, presente en Campeche, mencionaba que las condiciones de los soldados mexicanos eran deplorables; sin paga y apenas alimentados, reclutados por la fuerza en todo el país, servían en contra de su voluntad y preferían entregarse o huir hacia Guatemala tomando el antiguo camino real. Cubiertos de piojos, enfermos de fiebre amarilla, vómito, disentería, poco y mal alimentados, sufrían además de las inclemencias del sol y de la humedad propia de la región. ${ }^{6}$ En cuanto a los mayas, quienes constituían la mayoría del ejército yucateco, tenían una profunda aversión por las armas y huían en los bosques al menor descuido.

El reclutamiento de los soldados del ejército federal así como su composición social forman parte de un ángulo historiográfico muerto tanto en

de S. Miguel, Pandectas hispano-megicanas..., v. 2, 109-110. Véanse también los trabajos de José Daniel Ramírez Reyes, "Preparando a las Fuerzas armadas para un enfrentamiento inminente. La organización del Ejército mexicano de 1839”, en Memoria del 1er. Congreso Nacional de Historia Militar de México a través de los Archivos Históricos, v. 1 (México: Secretaría de la Defensa Nacional, Dirección General de Archivo e Historia, 2015), 317-326; Xochitl Martínez González, "La enseñanza primaria e instrucción del soldado del ejército permanente mexicano en la primera mitad del siglo XIX”, Tiempo y Espacio, n. 64 (juliodiciembre 2015): 331-350.

${ }^{5}$ Convención entre Miguel Barbachano y Juan de Dios Cosgaya, plenipotenciarios del Gobierno de Yucatán y Andrés Quintana Roo, plenipotenciario de México enviado por el General Santa Anna, 28 de diciembre de 1841, El Cosmopolita, 26 marzo de 1842, 2.

${ }^{6}$ Carta de Laisné de Villevêque al Ministro de Asuntos Extranjeros, 4 de julio de 1843, Archivo del Ministerio de Asuntos Extranjeros, Courneuve, Francia (en adelante AmaE), Fondo: Correspondance Consulaire et Commerciale, Campeche, t. 2, fs.171-172. 
el nivel nacional como en el regional. ${ }^{7}$ El ejército federal es percibido como una masa compacta de hombres desprovistos de cara, de identidad, de pasado y de otro interés más que el de luchar contra los que rechazan la civilización y ponen en riesgo el progreso y la paz. En efecto, al estudiar los conflictos armados a lo largo de la historia tanto colonial como moderna y contemporánea, la leva es mencionada como una práctica evidente y común, pero ¿quiénes eran esos soldados?, ¿de dónde venían?, ¿eran mayoritariamente indígenas arrebatados de su hogar y de su familia? Desafortunadamente no contamos en la actualidad con estudios analíticos con base en las filiaciones militares presentes en Yucatán, testimonios vivenciales o recursos legales que nos darían un panorama de los reclutas voluntarios, forzosos, difuntos, enfermos y desertores. De allí el objetivo principal de este artículo que toma como fuente de estudio los juicios de amparo interpuestos ante el Tribunal de Campeche por soldados reclutados en contra de su voluntad y asignados en uno de los batallones del ejército federal presentes en las colonias militares del estado de Campeche, una fuente poco estudiada desde la perspectiva de la historia social. En un intento de sacarlos del anonimato, proponemos un primer acercamiento en la identificación de estos soldados al analizar los procedimientos de su reclutamiento mediante su hoja de filiación y sus historias de vida relatadas en primera persona durante su juicio. Para esto, seguimos tres ejes articulatorios: el uso del amparo por reclutamiento forzoso, las etapas del juicio y la composición social de estos hombres en búsqueda de su libertad. A manera indicativa, aludiremos a otro recurso legal en paralelo al amparo llamado excepción, usado por civiles para evadir su integración, esta vez, a la Guardia Nacional.

\section{El recurso de amparo por reclutamiento forzoso}

La falta de paga, las condiciones lamentables dentro de las filas y la misma brutalidad del reclutamiento obligaron al soldado a recurrir a la justicia

${ }^{7}$ Para los estudios centrados en el uso del amparo en relación con el ejército, citaremos a Mario Ramírez Rancaño, La justicia durante el Porfiriato y la Revolución, 1898-1914. Los amparos entre el ejército federal (México: Suprema Corte de Justicia de la Nación, 2010); "Ejército federal, jefes políticos, amparos, deserciones: 1872-1914", Estudios de Historia Moderna y Contemporánea de México, n. 47 (enero-junio 2014): 41-78, http://dx.doi. org/10.1016/S0185-2620(14)70334-2; y a Timothy M. James, "Illegal Military Recruitment and Constitutional Law: The Judicial Protection of Forced Recruits in Late Nineteenth-Century Mexico", The America 76, n. 3 (2019): 415-442, https://doi.org/10.1017/tam.2019.32. 
gracias a las sucesivas leyes de amparo que permitieron reglamentar las pautas que debía seguir la Corte Suprema de Justicia contra las violaciones a partir de la Constitución Federal de 1857: la Ley orgánica de los artículos 101 y 102 de la Constitución, del 30 de noviembre de 1861; la Ley orgánica Constitucional sobre el recurso de amparo, del 20 de enero de 1869; y la Ley orgánica de los artículos 101 y 102 de la Constitución Federal del 5 de febrero de 1857 , emitida el 14 de diciembre de $1882 .{ }^{8}$ Subrayamos que durante el separatismo con México, el gobierno de Yucatán en el artículo 8 de su Constitución de 1841 había establecido la figura del amparo propuesta por Manuel Crescencio Rejón, considerado uno de sus precursores. ${ }^{9}$

Así, a partir de estas leyes a favor de las garantías individuales, los soldados reclutados por la fuerza tuvieron la posibilidad de interponer mecanismos legales ante el Tribunal para poder librarse del servicio de las armas. Si bien hubo que esperar a 1857 para que se estableciera este aparato legal con carácter constitucional y a 1861 para la Ley de amparo, en el Tribunal de Campeche el primer expediente abierto por filiación en contra de la voluntad del quejoso tiene fecha de febrero de 1875 y se extendió hasta 1903, con base en la Ley orgánica de 1869 y la de 1882, referidas por el juez del Tribunal de distrito de Campeche.

En el archivo de la Casa de la Cultura Jurídica en Campeche, contamos con un total de 63 juicios interpuestos por 96 hombres (cuadro 1). Así, en 1875 se abrió el primer caso de amparo por este motivo durante la presidencia de

${ }^{8}$ Los artículos de las tres leyes fueron publicados en el periódico Siglo Diez y Nueve. Ley orgánica de procedimientos de los tribunales de la federación que ecsige [sic] el artículo 102 de la Constitución Federal para los juicios de que habla el artículo 101 de la misma emitida el 30 de noviembre de 1861, en Siglo Diez y Nueve, 10 de diciembre de 1861, 1; la Ley orgánica de los artículos 101 y 102 de la Constitución sobre el recurso de amparo emitida el 20 de enero de 1869, en Siglo Diez y Nueve, 28 de enero de 1869, 1; la Ley orgánica de los artículos 101 y 102 de la Constitución de la República emitida el 14 de diciembre de 1882, en Siglo Diez y Nueve, 29 de diciembre de 1882, 1. Véase también el estudio histórico sobre las modificaciones a la ley de amparo en José Luis Soberanes Fernández, "Surgimiento del amparo judicial”, en El juicio de amparo a 160 años de la primera sentencia, coord. de Manuel González Oropeza y Eduardo Ferrer Mac-Gregor (México: Universidad Nacional Autónoma de México, 2011), 465-484.

${ }^{9}$ Jesús Ángel Arroyo Moreno, "El origen del juicio de amparo", en La génesis de los derechos humanos en México, coord. de Margarita Moreno-Bonett y María del Refugio González Domínguez (México: Universidad Nacional Autónoma de México, Instituto de Investigaciones Jurídicas, 2006), 60; Sergio Valls Hernández, "El juicio de amparo a 160 años de la primera sentencia”, en El juicio de amparo a 160 años de la primera sentencia, coord. de Manuel González Oropeza y Eduardo Ferrer Mac-Gregor (México: Universidad Nacional Autónoma de México, 2011), 528; José F. Palomino Manchego, “La primera sentencia de amparo en México (Un antecedente de historia constitucional)”, en El juicio de amparo a 160 años..., 336. 


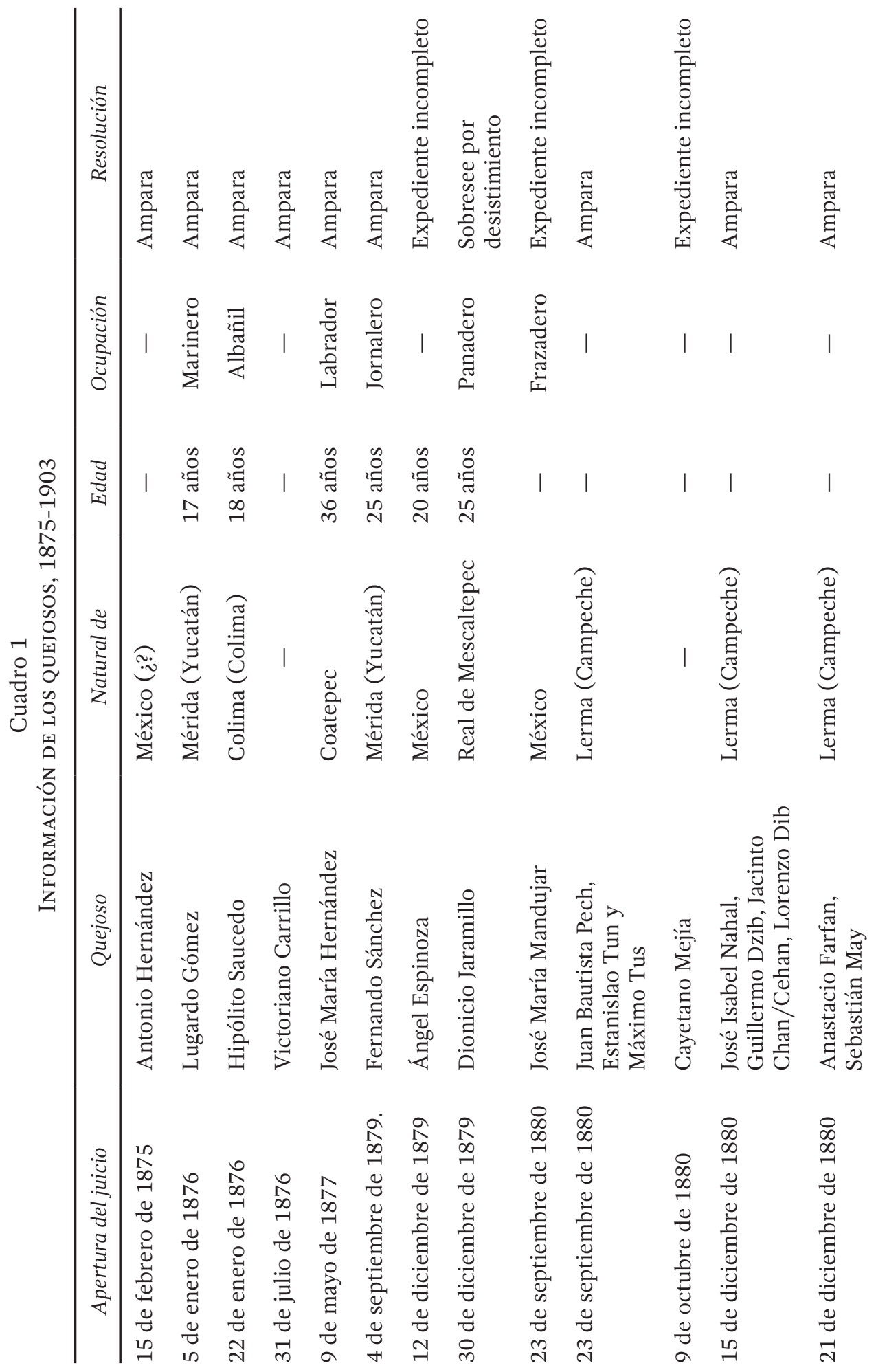



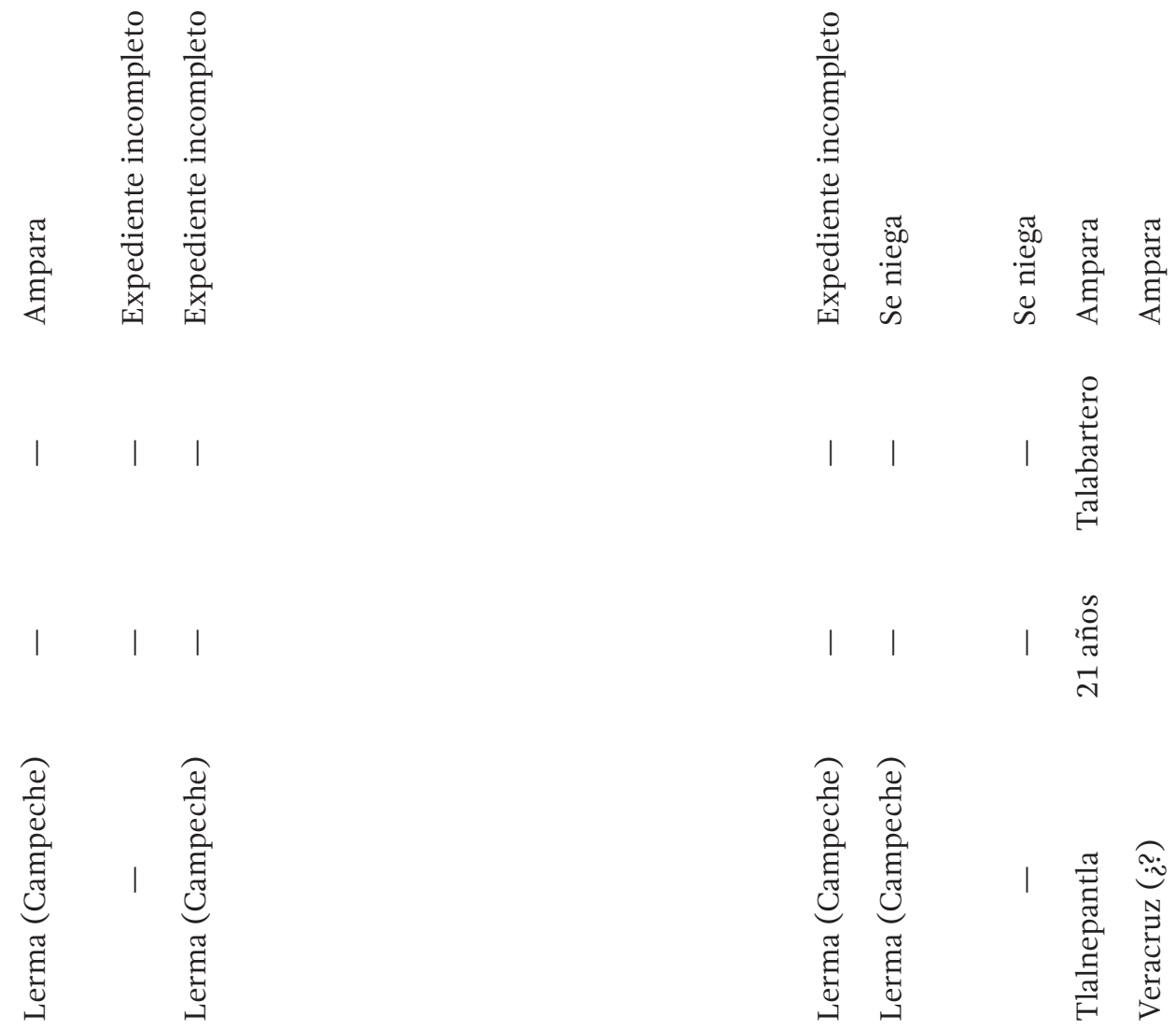

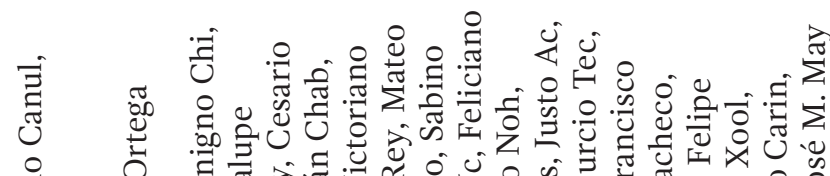

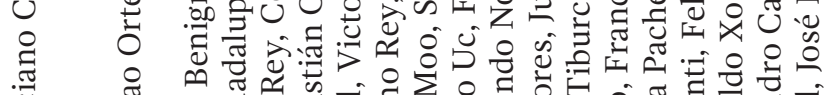

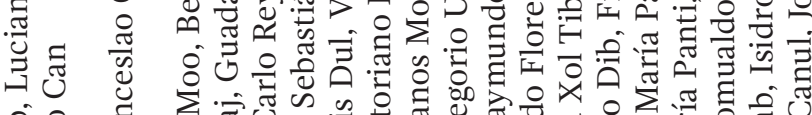

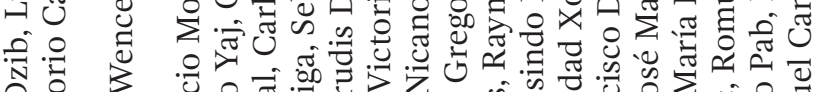

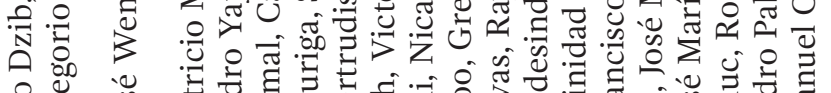

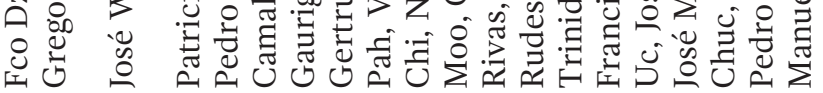
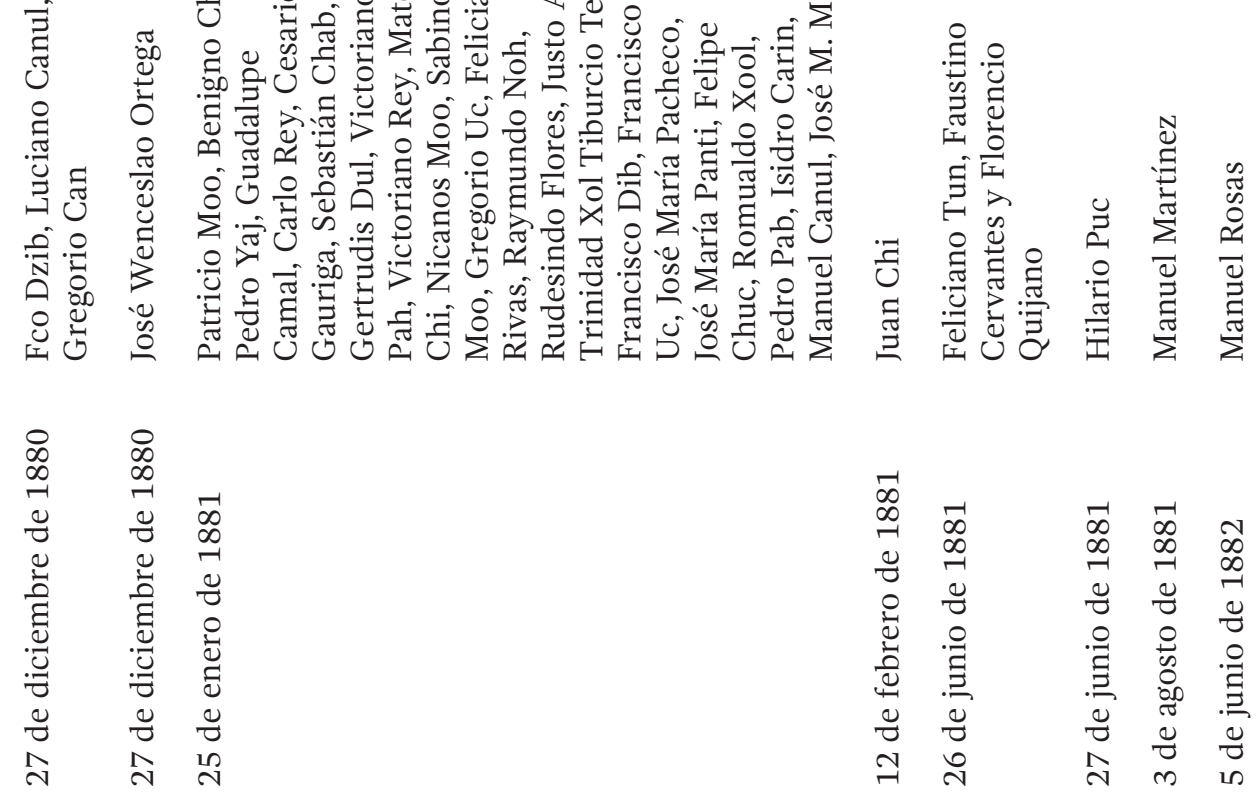


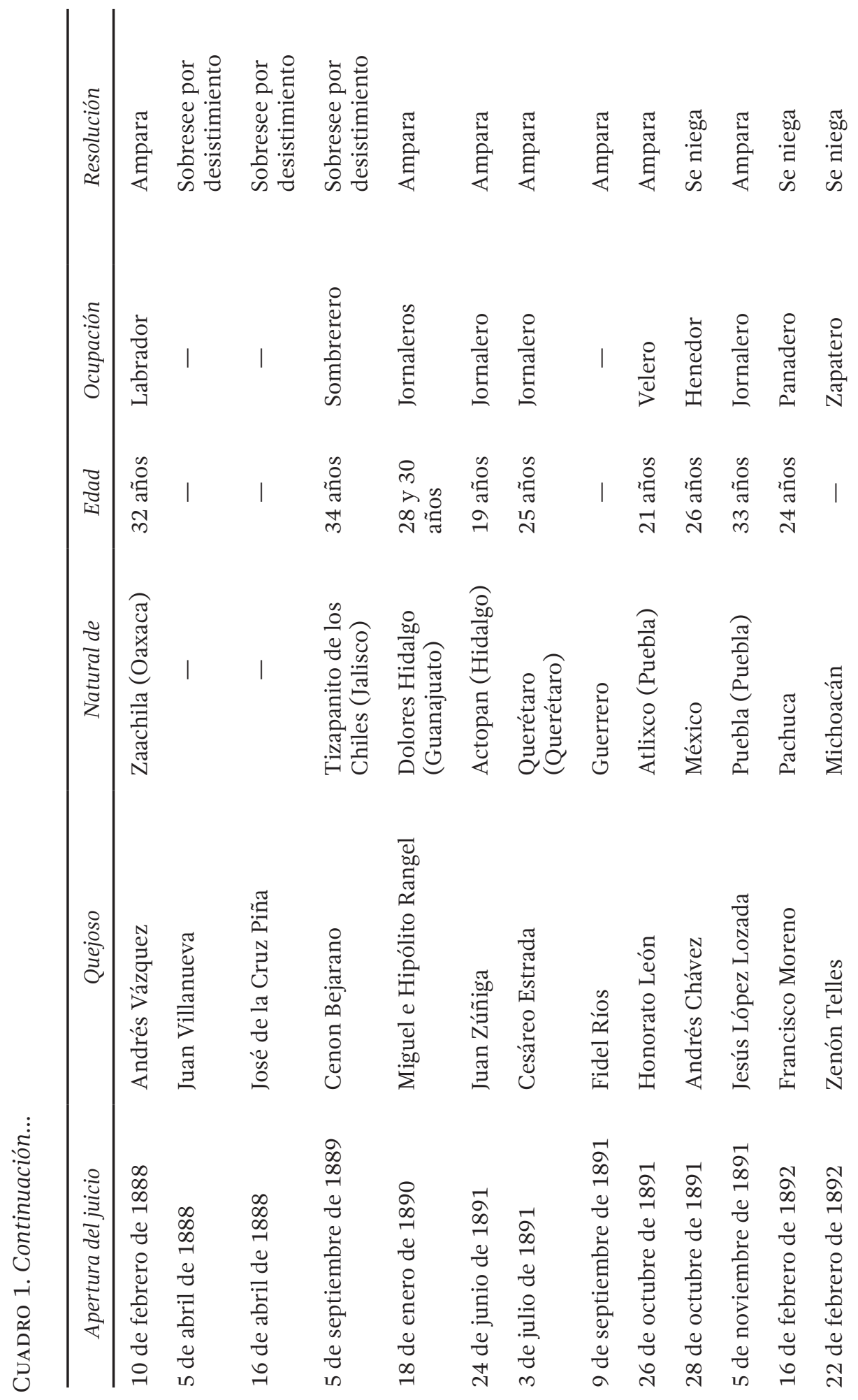




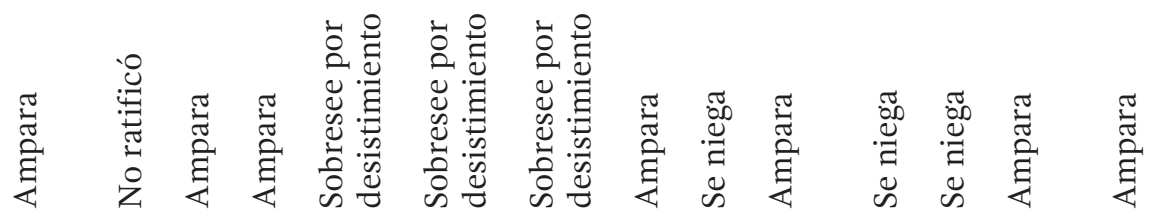

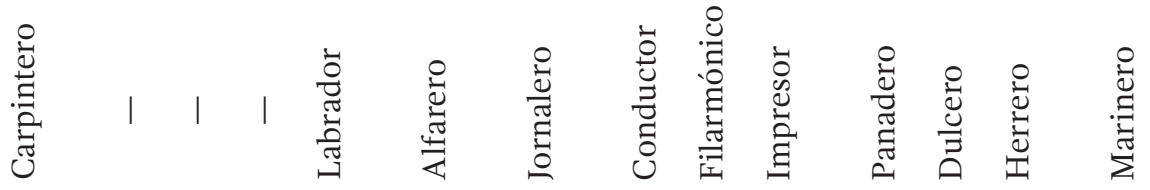

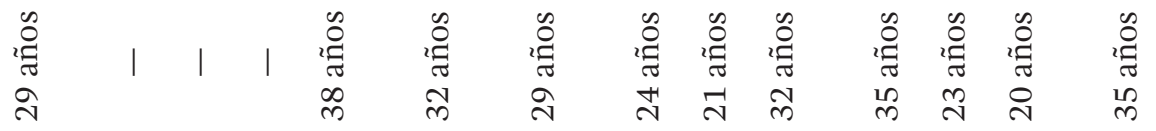

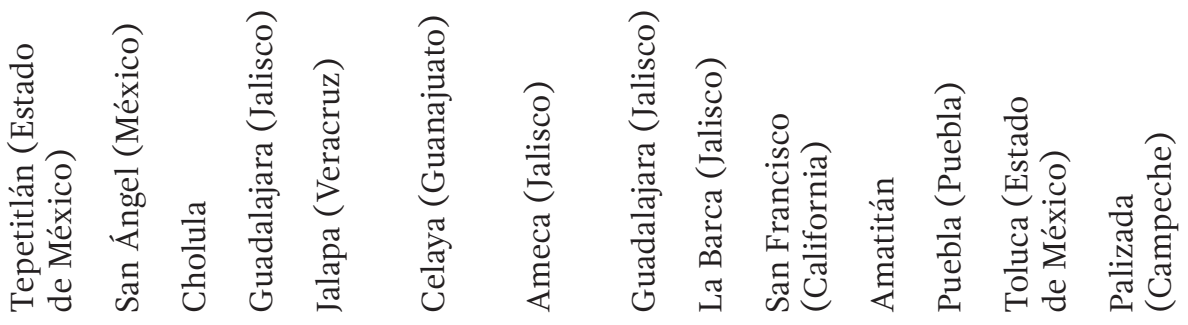

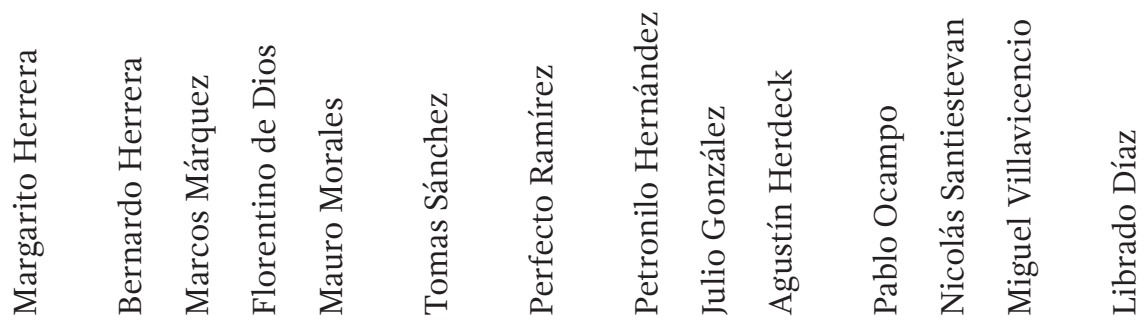

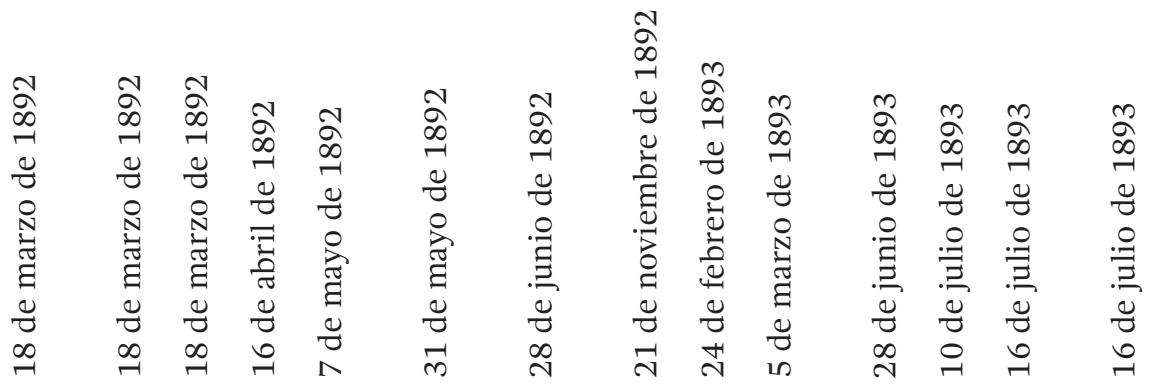




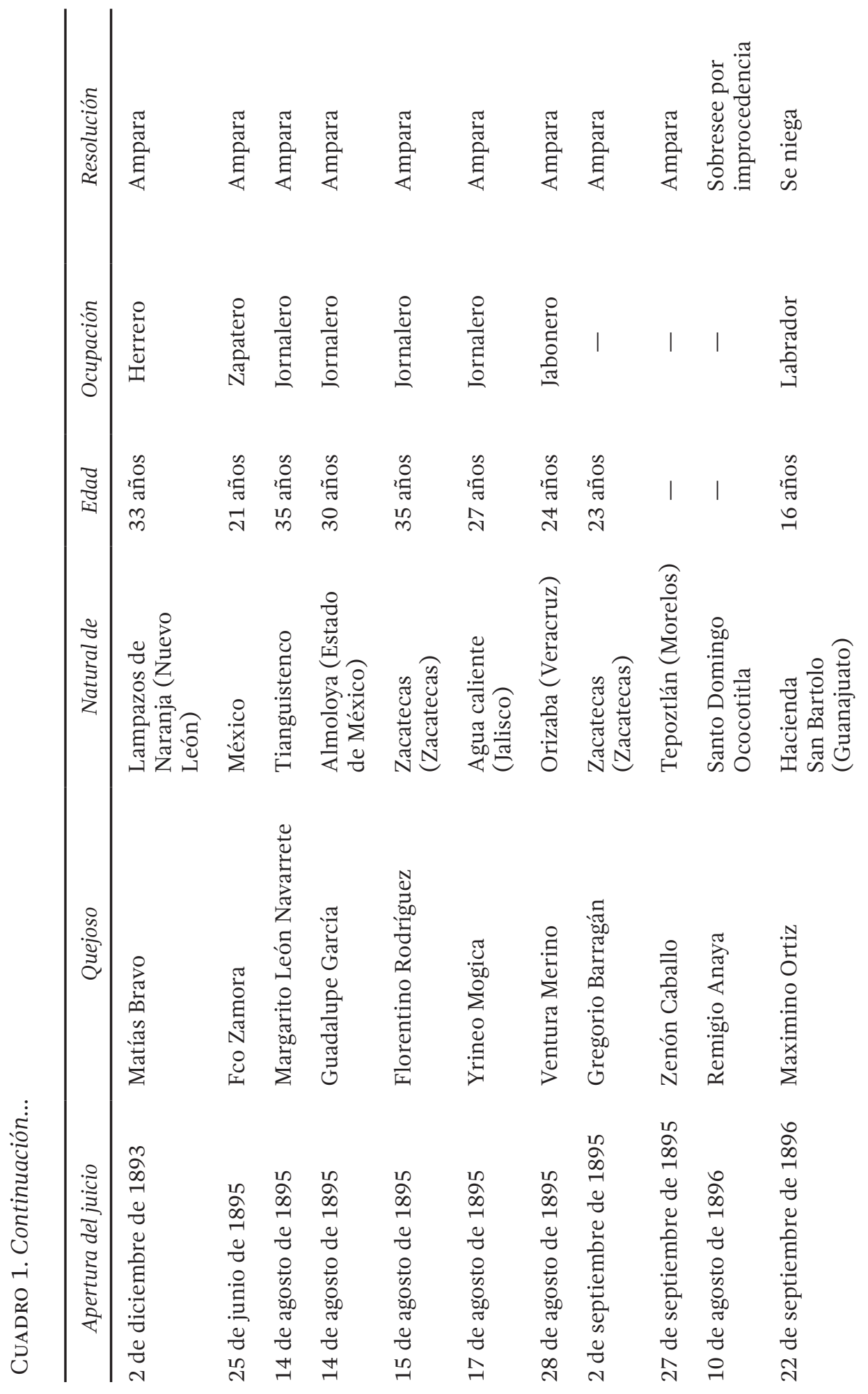




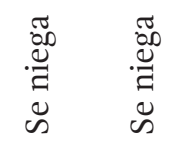

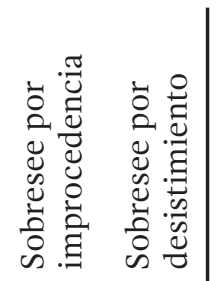

|

|

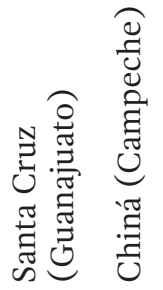

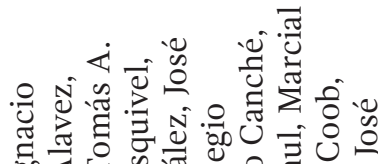

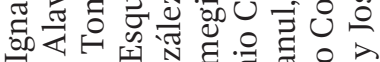

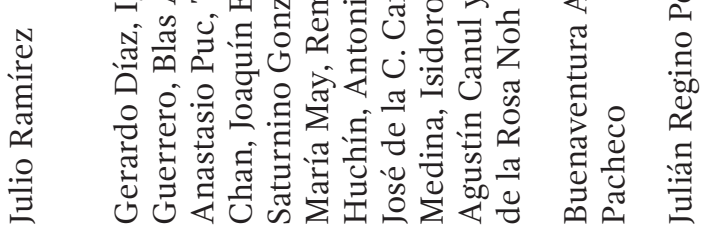

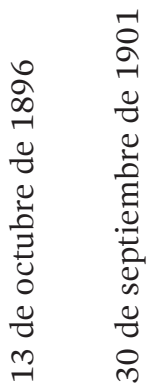

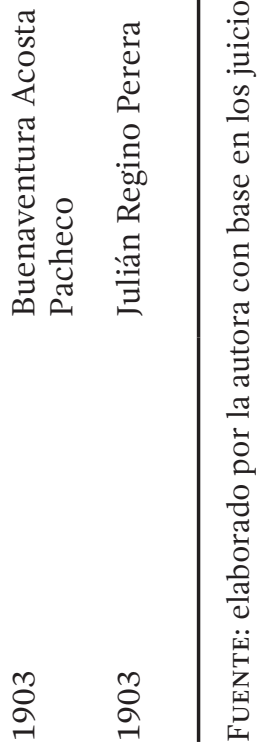


Lerdo de Tejada, coincidiendo con la afirmación de Ramírez Rancaño de que en el nivel nacional "no obstante la vigencia de la Constitución política de 1857, durante las guerras de Reforma e Intervención francesa casi no hubo amparos"10 (gráfica 1). Otra coincidencia con este autor es en la reducción significativa del amparo en el ámbito nacional a partir de 1883; en Campeche, entre los años 1883-1887 y 1897-1900, la solicitud fue nula quizás porque "no hubo demasiada presión gubernamental para reclutar candidatos para la tropa". ${ }^{11}$ Un contingente de hombres levantados en disminución en el ejército federal ante el aumento de civiles obligados a incorporarse a las compañías de la Guardia Nacional podría ser una hipótesis válida para explicar tal disminución. Los años 1891-1895 muestran al contrario un ligero aumento, años durante los cuales hubo una recrudescencia militar con la llegada de 800 tropas federales que se agregaban a las 500 ya presentes en Yucatán, ${ }^{12}$ listas para combatir a los mayas rebeldes.

\section{Las etapas del juicio}

El juicio pasaba por varias etapas: la demanda de amparo presentada por el soldado; su ratificación junto con la presentación de dos testigos; la argumentación de la autoridad militar con el anexo de la hoja de filiación; el alegato del promotor fiscal; la sentencia emitida por el juez; la ejecutoria por parte de la Suprema Corte de Justicia de la Nación; y finalmente la confirmación por parte de la Secretaría de Guerra y Marina.

El caso se abría en el momento en que el interesado, en este caso el soldado, presentaba un escrito de demanda - llamado ocurso- ante el juez del Tribunal de Campeche, es decir, una carta redactada en primera persona pero muy a menudo firmada por otra porque la mayoría de los soldados no sabía ni leer ni escribir. Este ocurso era en contra del jefe militar del batallón en el que había sido incorporado - siempre y cuando estuviera establecido dentro de la jurisdicción del estado de Campeche- o en contra del alcalde de su pueblo de origen, ambos ejecutores de las órdenes del ejército como autoridad. En una o dos cuartillas contaba la manera en que había sido brutal y violentamente filiado en contra de su voluntad para

${ }^{10}$ Ramírez Rancaño, “Ejército federal, jefes políticos...”, 57.

${ }^{11}$ Ramírez Rancaño, La justicia durante el Porfiriato..., 18.

12 Don Edmond Dumond, El machete y la cruz (México: Universidad Nacional Autónoma de México/Plumsock Mesoamerican Studies/Maya Educational Foundation, 2005), 582. 
prestar su servicio en el ejército. Alegaba que se habían violado los artículos de la Constitución Federal de 1857, en particular el artículo 5, porque se le obligaba a prestar trabajo personal sin pleno consentimiento, y el 16 porque se molestaba su persona sin mandamiento de autoridad competente que fundara y motivara la causa legal del procedimiento. ${ }^{13}$ Porque cada relato de vida y cada juicio era diferente, en contados casos los quejosos hacían referencia también a los artículos 1 (Ventura Merino), 4 (Mauro Morales), 11 (Perfecto Ramírez y Petronilo Hernández), 17 (Honorato León), 18 (Florentino de Dios), 19 (Fidel Ríos y Francisco Moreno), 21 (Gregorio Barragán) y 101 (Librado Díaz, Julio González y Agustín Herdeck). ${ }^{14}$

${ }^{13}$ Constitución Federal de los Estados Unidos Mexicanos, 1857: "Artículo 5. Nadie puede ser obligado a prestar trabajos personales, sin la justa retribución y sin su pleno consentimiento. La ley no puede autorizar ningún contrato que tenga por objeto la pérdida, o el irrevocable sacrificio de la libertad del hombre, ya sea por causa de trabajo, de educación, o de voto religioso. Tampoco puede autorizar convenios en que el hombre pacte su proscripción o destierro." "Artículo 16. Nadie puede ser molestado en su persona, familia, domicilio, papeles y posesiones, sino en virtud de mandamiento escrito de la autoridad competente, que funde y motive la causa legal del procedimiento. En el caso de delito infraganti, toda persona puede aprehender al delincuente y a sus cómplices, poniéndolos sin demora a disposición de la autoridad inmediata”.

${ }^{14}$ Constitución Federal de los Estados Unidos Mexicanos, 1857: "Artículo 1. El pueblo mexicano reconoce que los derechos del hombre son la base y el objeto de las instituciones sociales. En consecuencia declara que todas las leyes y todas las autoridades del país deben respetar y sostener las garantías que otorga la presente Constitución." "Artículo 4. Todo hombre es libre para abrazar la profesión, industria o trabajo que le acomode, siendo útil y honesto, y para aprovecharse de sus productos. Ni uno, ni otro se le podrá impedir, sino por sentencia judicial cuando ataque los derechos de tercero, o por resolución gubernativa, dictada en los términos que marque la ley, cuando ofenda los de la sociedad." "Artículo 11. Todo hombre tiene derecho para entrar y salir de la república, viajar por su territorio y mudar de residencia sin necesidad de carta de seguridad, pasaporte, salvoconducto u otro requisito semejante. El ejercicio de este derecho no perjudica las legítimas facultades de la autoridad judicial o administrativa, en los casos de responsabilidad criminal o civil." "Artículo 17. Nadie puede ser preso por deudas de un carácter puramente civil. Nadie puede ejercer violencia para recobrar su derecho. Los tribunales estarán siempre expeditos para administrar justicia. Esta será gratuita, quedando en consecuencia abolidas las costas judiciales." "Artículo 18. Sólo habrá lugar a prisión por delito que merezca pena corporal. En cualquier estado del proceso en que aparezca que al acusado no se le puede imponer tal pena, se pondrá en libertad bajo de fianza. En ningún caso podrá prolongarse la prisión o detención por falta de pago de honorarios, o de cualquiera otra ministración de dinero." "Artículo 19. Ninguna detención podrá exceder del término de tres días, sin que se justifique con un auto motivado de prisión y los demás requisitos que establezca la ley. El solo lapso de este término constituye responsables a la autoridad que la ordena o consiente, y a los agentes, ministros, alcaides o carceleros que la ejecuten. Todo maltratamiento en la aprehensión o en las prisiones, toda molestia que se infiera sin motivo legal, toda gabela o contribución en las cárceles es un abuso que deben corregir las leyes, y castigar severamente las autoridades.” “Artículo 21. La aplicación de las penas, propiamente tales, es exclusiva de la autoridad judicial. 
La siguiente etapa en el juicio era la ratificación de su declaración ante el Tribunal de Campeche, momento para aportar algún detalle y para presentar dos testigos ante el juez, quienes eran camaradas de su misma compañía y muchas veces del mismo pueblo que él, para rendir declaraciones y confirmar su pobreza porque sólo recibía como soldado 31 centavos de sueldo diario de los cuales se le descontaba la comida. De este modo el quejoso era exento de pagar las estampillas, que era el costo del juicio; sólo en tres ocasiones el juez exigió la reposición de éstas porque no se había declarado formalmente insolvente. Dos llamados a atestiguar la insolvencia de su compañero aprovecharon para interponer un amparo: Agustín Herdeck y Perfecto Ramírez, ${ }^{15}$ ambos sacados a la fuerza de su hogar de origen, filiados sin su voluntad y enviados lejos de su pueblo en los campamentos de la península.

Por su parte, la autoridad presentaba las pruebas requeridas por el juez: un oficio firmado por el jefe del batallón al que se anexaba la filiación del soldado. Una vez enunciados los autos del promotor fiscal, ${ }^{16}$ el juez dictaba la sentencia que, como en la actualidad, podía ser en los siguientes sentidos generales: se ampara y protege, es decir que el soldado debía ser inmediatamente dado de baja y podía regresar con sus familiares; se niega el amparo por lo cual debía permanecer en el ejército; o bien se sobresee, es decir que el juicio se suspendía porque el soldado no se había presentado para ratificar o porque los familiares habían interpuesto un amparo en el tribunal de su pueblo de origen. Para que el juicio cerrara, la sentencia tenía

La política o administrativa sólo podrá imponer, como corrección, hasta quinientos pesos de multa, o hasta un mes de reclusión, en los casos y modo que expresamente determine la ley." "Artículo 101. Los tribunales de la federación resolverán toda controversia que se suscite: I. Por leyes o actos de cualquiera autoridad que violen las garantías individuales. II. Por leyes o actos de la autoridad federal que vulneren o restrinjan la soberanía de los Estados. III. Por las leyes o actos de las autoridades de éstos que invadan la esfera de la autoridad federal".

15 Juicio de amparo promovido por Agustín Herdeck, soldado del 1er. cuerpo de batallón contra actos del jefe de dicho cuadro por violación de los artículos 9, 14, 15, 16, 58 y 101 de la Constitución Federal, 1893, ccJc, Amparo, caja 63, exp. 9; Juicio de amparo promovido por el soldado Perfecto Ramírez, contra su consignación al servicio de las armas con el 1er. cuerpo de batallón que reside en esta plaza por creer violadas en su perjuicio las garantías que protegen artículos 5, 11 y 16 de la Constitución Federal, 1892, ccJc, Amparo, caja 62, exp. 19.

${ }^{16}$ El promotor fiscal, cuya figura existía desde la época colonial, estaba presente en cada juzgado de Distrito y de Circuito y tenía a su cargo la acusación en el juicio penal. Su equivalente hoy es el Ministerio Público. Sergio García Ramírez, "El Ministerio Público, en El Ministerio Público en el Distrito Federal (México: Universidad Nacional Autónoma de México, Instituto de Investigaciones Jurídicas/Procuraduría Federal de Justicia, 1997), 1. 
que ser revisada por la Suprema Corte de Justicia de la Nación en México y regresada al juez de Campeche. ${ }^{17}$

El tiempo transcurrido entre la solicitud del quejoso y la sentencia del juez de Campeche era aproximadamente de mes y medio a dos meses porque el Tribunal tenía que cumplir con los tiempos que marcaba la ley orgánica del recurso de amparo, más lo que tardaba la Suprema Corte en reenviar a Campeche la ejecutoria, la cual requería entre tres y seis semanas.

Sin embargo, el juicio podía demorar mucho más por dos razones. Cuando el coronel del batallón en el que estaba filiado el soldado y sus dos testigos decidía mandarlos al día siguiente de haber depositado su ocurso a las colonias militares de Iturbide (Campeche) o de Peto (Yucatán), retrasando así su ratificación presencial ante el juez del Tribunal. Y cuando, a pesar de la confirmación de la Suprema Corte de Justicia, el coronel daba de baja al soldado tan luego recibiera la orden por parte de la Secretaría de Guerra, pero la recepción de esa orden solía demorar, lo que representaba una espera adicional de seis meses hasta un año. ${ }^{18}$ Era una deliberada estrategia para retrasar un juicio en que la autoridad militar sabía que estaba a punto de perder a un elemento. Entre todos los comandantes de los batallones del periodo estudiado, ${ }^{19}$ a partir de 1895, el coronel Juvencio Robles fue el más inclinado en prolongar el tiempo del soldado amparado bajo muy tramposos pretextos, porque el juez se había equivocado en una letra del apellido ${ }^{20} \mathrm{o}$

${ }^{17}$ Ramírez Rancaño había identificado solamente tres casos de amparo confirmados por la Suprema Corte de Justicia de la Nación para la entidad federativa de Campeche entre 1872 y 1900. Ramírez Rancaño, “Ejército federal, jefes políticos...”, 74, véase la nota del cuadro 5.

${ }^{18}$ Florentino Rodríguez, 1895, Sentencia del juez del Tribunal de Campeche el 17 de octubre de 1895, la Secretaría de Guerra lo da de baja el 22 de agosto de 1896, CCJC, Amparo, caja 69, exp. 27; Gregorio Barragán, 1895, Sentencia del juez del Tribunal de Campeche el 18 de octubre de 1895, la Secretaría de Guerra lo da de baja el 6 de junio de 1896, ccJC, Amparo, caja 69, exp. 26; Florentino Rodríguez, 1895, Sentencia del juez del Tribunal de Campeche el 28 de septiembre de 1895, la Secretaría de Guerra lo da de baja el 22 de julio de 1896, ccJc, Amparo, caja 69, exp. 23.

${ }^{19}$ Estos son los jefes de batallones implicados en los juicios de amparo: Pedro Vidal, Batallón 14; Alberto A. Hoffman, Batallón 21; Benjamín Álvarez, Batallón 22; Lorenzo R., Batallón 23; José I. Flores y José María Echavarría, comandantes de la Guardia Nacional; José María Heredia, comandante de la colonia de Iturbide; Fernando F. Lapham, comandante de las armas militares, Jesús Oliver y J. López Aguedo de la 11a. zona militar.

${ }^{20}$ Telegrama de Juvencio Robles al juez en el que pide la rectificación de la orden de baja al cuartel general pues ésta dice Moreno en vez de Merino, f. 20. Juicio de amparo promovido por Ventura Merino soldado de la 1a. compañía del 22 batallón contra actos del Coronel del cuerpo por violación de los artículos 1, 5 y 16 de la Constitución Federal, 1895, CCJC, Amparo, caja 69, exp. 23. 
porque "en virtud de haber dejado en la plaza de Mérida al emprender la marcha el batallón todo el archivo y papeleras del expresado, no se puede rendir el informe a que se refiere por falta de datos" ${ }^{21} ¿$ Estricta obediencia de los procedimientos militares? La reputación de cruel y sangriento de este militar contra la población civil durante la Revolución mexicana hace inclinar la balanza más bien hacia una voluntad personal de abuso de autoridad.

\section{Filiación y composición social}

Todos los juicios de amparo involucraban a hombres de entre 16 y 38 años, tanto casados como solteros, es decir, una población masculina y en su mayoría analfabeta. La diversidad de las profesiones mecánicas (jornaleros en su mayoría, pero también había herreros, carpinteros, panaderos, frazaderos, sombrereros, pequeños comerciantes, talabarteros, músicos) permitía cubrir todas las faenas dentro y fuera de los cuarteles, pero era un marcador social que acentuaba la distancia con respecto a los altos rangos quienes habían recibido una educación militar.

Citado a diestro y siniestro, el caso de Perfecto Ramírez, 29 años, arriero, oía misa en su pueblo de Ameca (Jalisco) cuando fue aprehendido y luego reducido a prisión varios días antes de ser filiado por la fuerza y conducido a Veracruz y de allí a Yucatán. ${ }^{22}$ El de Cenon [sic] Bejarano, se encontraba ocupado en las faenas de su hogar en Tizapanito (Jalisco) cuando fue aprehendido e incorporado a la 1a. compañía del batallón 22, de allí a Veracruz, a Progreso, a Mérida y a Campeche. ${ }^{23}$ Lo mismo para Andrés Vázquez, en Zaachila (Oaxaca) junto con otros paisanos consignados al servicio de las armas. ${ }^{24} \mathrm{O}$ bien el caso de Manuel Rosa, quien estaba trabajando en el muelle de Progreso cuando fue "cogido de leva" por orden del

${ }^{21}$ Juicio de amparo promovido por Zenón Caballo soldado del 22 batallón contra actos del Coronel del cuerpo por violación de los artículos 1, 5, 8 y 16 de la Constitución, 1895, CCJC, Amparo, caja 69, exp. 28, f. 6.

22 Juicio de amparo promovido por el soldado Perfecto Ramírez, contra su consignación al servicio de las armas con el 1er. cuerpo de batallón que reside en esta plaza por creer violadas en su perjuicio las garantías que protegen artículos 5, 11 y 16 de la Constitución Federal, 1892, cCJc, Amparo, caja 62, exp. 19.

${ }^{23}$ Juicio de amparo promovido por Cenon Bejarano contra su consignación forzada al servicio de las armas en el Batallón 22, 1889, ccJc, Amparo, caja 54, exp. 17.

${ }^{24}$ Amparo promovido por Andrés Vázquez contra actos del capitán del Batallón 22 residente en esta plaza por creer violadas en su persona las garantías que otorgan los artículos 5 y 16 de la Constitución General, 1888, cCJC, Amparo, caja 53, exp. 4. 
jefe del batallón 25, que se encontraba en el puerto, y consignado al mismo batallón. ${ }^{25}$ En dos casos, el de José María Hernández ${ }^{26}$ de Coatepec (Veracruz) y de Fernando Sánchez de Mérida (Yucatán), ${ }^{27}$ fueron aprehendidos y filiados por "vagos y perniciosos", una persecución con fundamento legislativo que había permeado la época colonial; ${ }^{28}$ una de las medidas para su reducción era reunirlos en las filas militares. ${ }^{29}$

Hemos detectado en total 41 lugares de origen de esos hombres procedentes de toda la república mexicana, en particular del centro del país; entre ellos, cinco eran de la capital, un extranjero y nacionalizado originario de San Francisco (California, Estados Unidos), y para ocho hombres no se pudo identificar su procedencia (mapa 1). Después de varios días en detención, eran trasladados de sus pueblos rumbo al puerto de Veracruz donde los embarcaban hacia la península de Yucatán.

En el caso del Tribunal de Campeche, 55\% de los juicios terminaban a favor del individuo porque se había podido comprobar que no había sido ni por sorteo ni por enganche voluntario, únicos medios legales de reemplazar las bajas del ejército de acuerdo al artículo 2 del Reglamento de la Ley General del 28 de mayo de 1869, ${ }^{30}$ sino por consignación de las autoridades y de la Secretaría de Guerra y Marina, violando sus libertades individuales

${ }^{25}$ Amparo promovido por Francisco Rosas en representación de un hermano Manuel por violación del artículo 5 de la Constitución General, 1882, cCJC, Amparo, caja 46, exp. 14.

${ }^{26}$ Autos de juicio de amparo promovido por el ciudadano José María Hernández por haber sido destinado contra su voluntad al servicio de las armas, 1877, cCJC, Amparo, caja 40, exp. 4.

${ }^{27}$ Diligencia de juicio de amparo promovido por Fernando Sánchez, soldado de la 4a. compañía del batallón 21, por haberse violado en su persona el artículo 5 de la Constitución Federal, 1879, cсJC, Amparo, caja 41, exp. 7.

${ }^{28}$ Norma Martin, "Pobres, mendigos y vagabundos en la Nueva España, 1702-1766", Estudios de Historia Novohispana, n. 3 (1985), http://dx.doi.org/10.22201/iih.24486922e.1985.008.3285; Sonia Pérez Toledo, "Los vagos de la ciudad de México y el Tribunal de Vagos en la primera mitad del siglo xıx”, Secuencia, n. 27 (1993), http://dx.doi. org/10.18234/secuencia.v0i27.436.

${ }^{29}$ José Antonio Serrano Ortega, El contingente de sangre. El reclutamiento del ejército permanente mexicano, 1824-1846 (México: Instituto Nacional de Antropología e Historia, 1993); y del mismo autor: "Levas, Tribunal de Vagos y Ayuntamiento: la ciudad de México, 1825-1836", en La experiencia institucional en la ciudad de México. 1821-1929, ed. de Carlos Illades y Ariel Rodríguez Kuri (México: Universidad Autónoma Metropolitana-Iztapalapa/ El Colegio de Michoacán, 1996), 131-154.

${ }^{30}$ Artículo 2 del Reglamento para cubrir las bajas del ejército por medio del sorteo, conforme a la base establecida por la Ley General de 28 mayo 1869: "La Legislatura de cada Estado podrá sustituir el sorteo con el enganche de soldados voluntarios, siempre que sea eficaz para el cumplimiento de esta ley”, Boletín de la 4a. División Militar, 22 de julio 1869, 2. 
(gráfica 2). El jefe del batallón, en su oficio, afirmaba muy a menudo que el soldado había sido incorporado por enganche voluntario, y hasta se decía sorprendido de que acudiera al juzgado en demanda de amparo. A pesar de que era la palabra del soldado contra la de la autoridad militar, el juez otorgaba más crédito al quejoso, a menos que existiera una prueba irrefutable como, por ejemplo, la de Pablo Ocampo quien después de casi cinco años como soldado, había aceptado su ascenso a cabo " $\mathrm{y}$ haber servido con este carácter durante 1 año, 7 meses y 8 días en el batallón 22”, lo cual mostraba que estaba conforme en el ejército y era suficiente para que el juez le negara el amparo. ${ }^{31}$

Para los que habían sido levantados por orden del alcalde municipal o del jefe político de su pueblo de origen, algunos encontraron un apoyo inconmensurable en sus familiares: esposas, hermanos, padres, quienes interponían por ellos un amparo ante el Tribunal de su pueblo, ${ }^{32}$ de ahí que cuatro de los juicios fueron sobreseídos, es decir suspendidos, porque no se podía acudir al amparo dos veces por los mismos hechos o por violaciones en contra de la misma persona. ${ }^{33}$

31 Juicio de amparo promovido por Pablo Ocampo, soldado del 1er. cuerpo de batallón contra su consignación y retención en el servicio de las armas con violación del artículo 5 de la Constitución Federal, 1893, ccıc, Amparo, caja 63, exp. 24.

32 Juicio de amparo promovido por Gertrudis Rey a nombre de su marido Manuel Martínez por violarse en su persona las garantías que le otorgan los artículos 5 y 16 de la Constitución General de la República, 1881, ccJc, Amparo, caja 45, exp. 10; Esposas, madres, hermanas de Patricio Moo y socios, de Lerma por violación de la garantía que les concede el artículo 5 de la Constitución General de la República, 1881, cCJC, Amparo, caja 45, exp. 25; Amparo promovido por Gregoria Chuc en representación de su esposo Hilario Puc por violación de la garantía individual, 1881, ccJc, Amparo, caja 45, exp. 32; Amparo promovido por Francisco Rosas en representación de un hermano Manuel por violación del artículo 5 de la Constitución General, 1882, cCJc, Amparo, caja 46, exp. 14; Juicio de amparo promovido por Eufrasia Suárez a nombre de su esposo José de la Cruz Piña contra el jefe político de esta capital, Domingo Hurtado, por su consignación al servicio de las armas en las colonias militares de Iturbide por un tiempo indeterminado, 1888, сслC, Amparo, caja 53, exp. 7; Amparo promovido por Silveria Barrato contra actos del jefe político de esta capital, Domingo Hurtado, por consignación de su hijo Juan Villanueva al servicio de las armas en las colonias militares de Iturbide, 1888, cсJC, Amparo, caja 53, exp. 8; Juicio de amparo ante el juzgado de distrito de Guanajuato promovido por Felipe y Marcos Rangel [sus respectivos padres] en favor de Miguel e Hipólito Rangel contra el jefe de Dolores Hidalgo por violación de los artículos 5 y 16 de la Constitución General, 1890, ccJc, Amparo, caja 59, exp. 11.

${ }_{33}$ Amparo promovido por Silveria Barrato contra actos del jefe político de esta capital, Domingo Hurtado, por consignación de su hijo Juan Villanueva al servicio de las armas en las colonias militares de Iturbide, 1888, ccJC, caja 8, exp. 53; Juicio de amparo promovido por Eufrasia Suárez a nombre de su esposo José de la Cruz Piña contra el jefe político 
Gracias a que no se necesitaba ningún recurso financiero, ni fiador, ni representante legal, ni abogado, ni apoderado y hasta "los notoriamente pobres podrán usar de papel común para sus ocursos y actuaciones", ${ }^{34}$ de allí la posibilidad para los más desfavorecidos de recurrir a la justicia sin el riesgo de endeudarse. La dificultad residía en superar el abuso, la violencia, el desprecio, el rechazo, la burla, la humillación dentro del cuartel hasta que terminara el juicio. Para algunos la presión era tan fuerte que preferían no presentarse a ratificar "porque lo viene perjudicando y retiró la queja al momento de su comparecencia". ${ }^{35}$ En cuanto al trato que sufrían los que se habían atrevido a entablar un juicio en contra del ejército, y por ende en contra de la salvaguardia de la patria, Zenón Telles (de Michoacán), declaraba

que el soldado que está para cumplir o está amparado de su pena señalada lo obligan y lo exponen al precipicio por la oficialidad con las injurias y las palabras tan obscenas e infames con que se expresan, imponiendo los más injustos castigos y de hechos con mano armada. ${ }^{36}$

De los 96 hombres identificados, 16 habían sido desertores, algunos en dos y hasta en tres ocasiones, en vano. Las condiciones mismas del soldado dentro del cuartel podrían explicar las razones, aunque debemos pensar que este rechazo rotundo por las armas respondía también a otros factores como la falta de identidad nacional, más marcada en las regiones alejadas del altiplano central. En efecto, a semejanza de la frontera norte estudiada por Héau-Lambert y Rajchenberg, ${ }^{37}$ la península de Yucatán fue excluida

de esta capital, Domingo Hurtado, por su consignación al servicio de las armas en las colonias militares de Iturbide por un tiempo indeterminado, 1888, сслc, caja 7, exp. 53; "deseoso de salir del servicio militar promovió amparo en el estado de Veracruz y sin esperar allí el resultado lo pidió también en este estado al ser traído a Campeche por lo cual no puede seguirse el juicio porque no puede fallarse dos veces sobre el mismo asunto", 1889, cCJc, caja 54, exp. 17, f. 25, Zenón Bejarano; "sobresee por desistimiento el 27 julio de su queja por convenirle más seguir el recurso iniciado por su familia en México ante el juzgado de 2o. Distrito del D. F.”, 1892, cCJc, caja 19, exp. 62, f. 12, Perfecto Ramírez.

${ }^{34}$ Artículo 59 de la Ley orgánica de los artículos 101 y 102 de la Constitución Federal del 5 de febrero de 1857 emitida el 14 de diciembre de 1882.

${ }^{35}$ Demanda de amparo no ratificada promovida por Bernardo Herrera contra acto del jefe de las armas federales en el Estado, 1892, cCJc, Amparo, caja 62, exp. 51.

${ }^{36}$ Juicio de amparo promovido por Zenón Telles, soldado del 22 Batallón contra actos del coronel jefe de las fuerzas federales en el Estado que lo retiene en el servicio militar en violación del artículo 5 de la Constitución, 1893, cCJC, Amparo, caja 61, exp. 3.

${ }^{37}$ Catherine Héau-Lambert y Enrique Rajchenberg, "La identidad nacional. Entre la patria y la nación: México, siglo XIx”, Cultura y Representaciones Sociales 2, n. 4 (2008). 


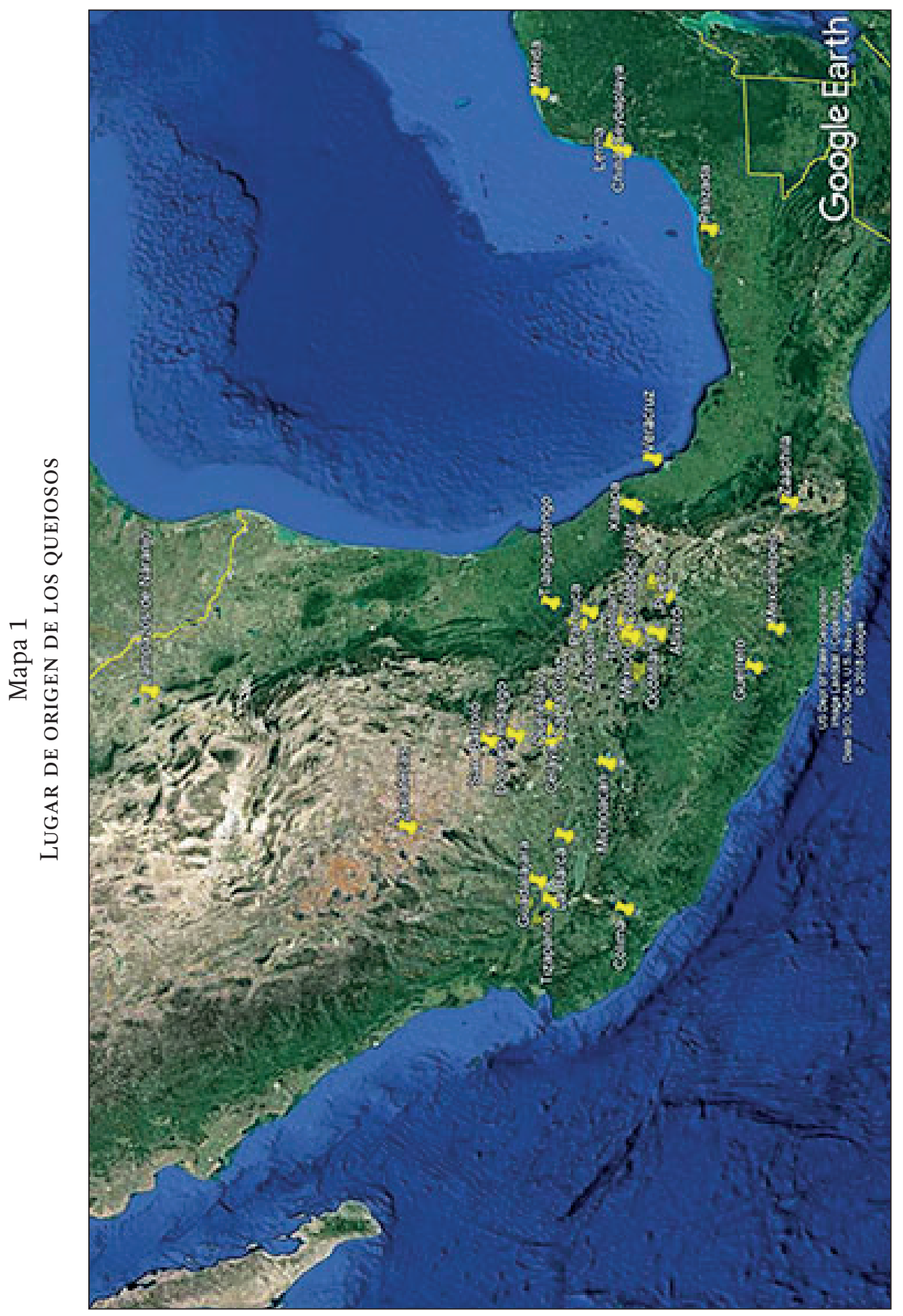

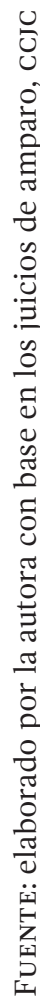


Gráfica 1

JUICIOS DE AMPARO POR RECLUTAMIENTO FORZOSO

1875-1903

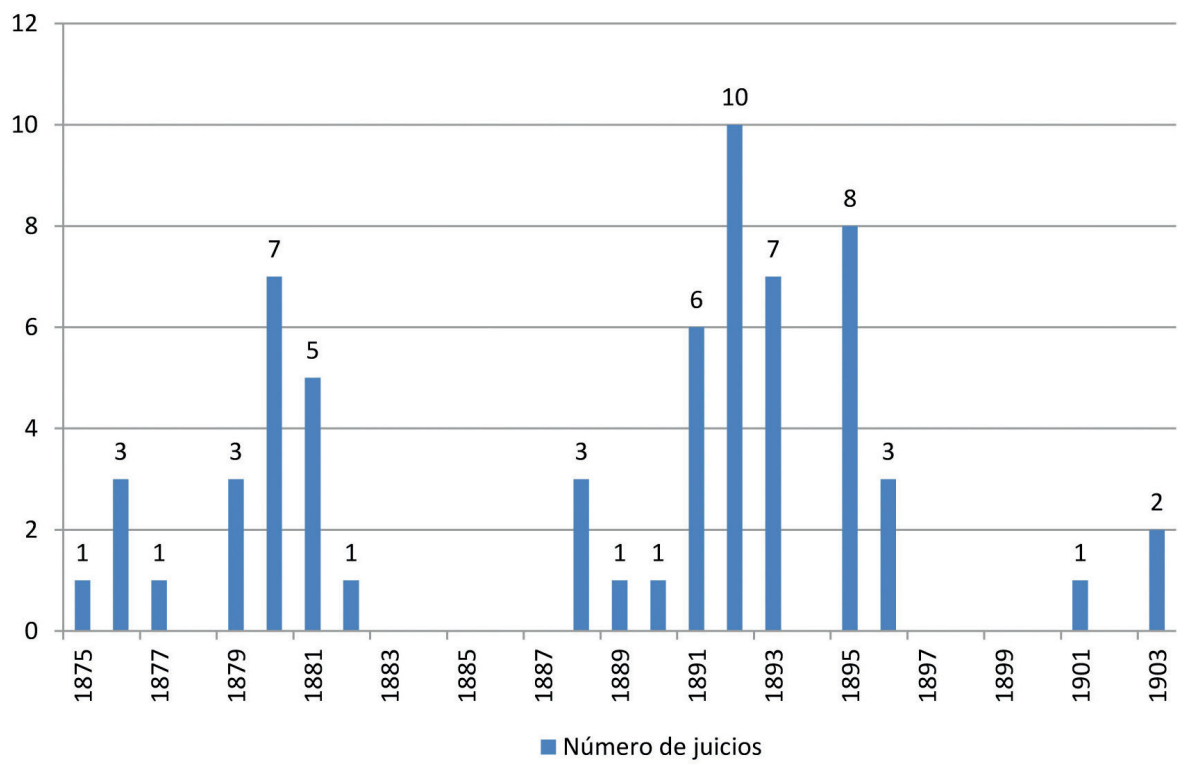

FuENTE: elaborado por la autora con base en los juicios de amparo, CCJC

Gráfica 2

SENTENCIA DiCTADA POR EL JUEZ

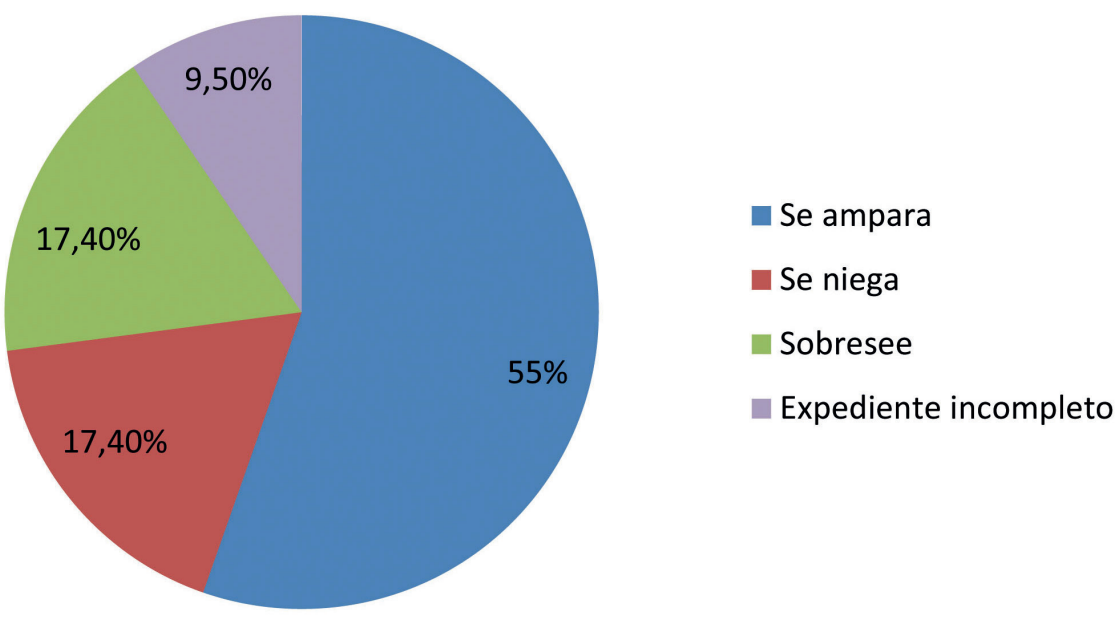

FUENTE: elaborado por la autora con base en los juicios de amparo, CCJC 
de la representación territorial de la nación, habitada en su mayoría por salvajes o bárbaros y con mucho espacio por civilizar; una visión proyectada desde la capital del país y también desde las cuatro ciudades con más población blanca en Yucatán: Mérida, Valladolid, Campeche y el Carmen a lo largo del siglo XIX. ${ }^{38}$ Así, el "neoaztequismo patriótico", al que aluden Héau-Lambert y Rajchenberg, ${ }^{39}$ excluyó al norte de México de las fronteras de la patria y, agregaríamos, al sur. Así, ser mexicano en el centro del país, definido como el espacio político-simbólico y orgullo identitario nacional, perjudicó a la hora de conformar un ejército plurirregional.

\section{La excepción de la Guardia Nacional}

Nos percatamos de que de los nueve juicios de amparo interpuestos por hombres con apellidos indígenas de los pueblos de Lerma y de Chiná (Campeche), quienes declararon que se habían violado las garantías individuales de los artículos 5 y 16 (véase la nota 13), ${ }^{40}$ cinco argumentaron que era para

38 Territorio, territorialidad, colonialidad y fronteras han sido trabajados por Rosa Torras Conangla desde la perspectiva del Carmen: La tierra firme de enfrente: la colonización campechana sobre la región de Los Ríos (siglo XIX) (Mérida: Universidad Nacional Autónoma de México, Centro Peninsular en Humanidades y Ciencias Sociales, 2012); y de Candelaria a finales del siglo XIX: Colonización y colonialidad en una selva de frontera. La Cuenca campechana del río Candelaria (siglos XIX y XX) (Mérida: Universidad Nacional Autónoma de México, Centro Peninsular en Humanidades y Ciencias Sociales, 2019).

${ }^{39}$ Héau-Lambert y Rajchenberg, "La identidad nacional...", 52.

${ }^{40}$ Juicio de amparo promovido por Estanislao Tun, Juan Bautista Pech y Máximo Tus, vecinos del pueblo de Lerma, contra las disposiciones del capitán de la compañía de la Guardia Nacional que violan en sus personas el artículo 5 de la Constitución General, 1880, cCJC, Amparo, caja 0, exp. 12; Juicio de amparo promovido por Francisco Dzib, Luciano Canul, Gregorio Can, vecinos del pueblo de Lerma, contra las disposiciones del capitán de la compañía de la Guardia Nacional que violan en sus personas los artículos 5 y 16 de la Constitución General, 1880, cCJc, Amparo, caja 0, exp. 13; Juicio de amparo promovido por José Isabel Nahal, Guillermo Dzib, Jacinto Chan/Cehan y Lorenzo Dib, del pueblo de Lerma, por violación de sus garantías individuales, 1880, ccJc, Amparo, caja 43, exp. 19; este caso aparece en Colección de las sentencias pronunciadas por los tribunales federales de la República, v. 2 (México: Imprenta de Francisco Díaz de León, Segunda época, 1882), 227-229. Amparo promovido por Juan Chi en representación de un hermano Ubaldo Chi por violación de la garantía individual, 1881, cCJC, Amparo, caja 45, exp. 5; Juicio de amparo promovido por Patricio Moo y socios por violación de la garantía que les concede el artículo 5 de la Constitución General de la República, 1881, ccJc, Amparo, caja 45, exp. 25; Amparo promovido por Gregoria Chuc en representación de su esposo Hilario Puc por violación de la garantía individual, 1881, cCJc, Amparo, caja 45, exp. 32; Juicio de amparo promovido por Feliciano Tun, Faustino 
evitar prestar servicio personal en las haciendas de Chapin y Chulbac, propiedades de Marcelino Castilla: ${ }^{41}$ limpiar camino, cortar palo de tinte, recoger el arroz, sembrar caña de azúcar sin remuneración; la sentencia falló siempre a favor de los quejosos. Mientras que para los cuatro juicios cuya razón era para no marchar a las colonias militares del cantón de Iturbide en la Guardia Nacional durante tres meses, el amparo no procedía porque era obligación del ciudadano campechano defender y sostener la existencia política del Estado y el orden público (con base en la ley particular de organización de la Guardia Nacional en el Estado, artículo 42 fracción I), obligación definida igualmente por la ley federal del 13 julio de 1848 sobre organización y servicio de la Guardia Nacional. Así, marchar al cantón de Iturbide, "puesto avanzado en nuestras fronteras con los lugares ocupados por los indios sublevados", era prestar un servicio de conservación del orden público, garantizar la paz y defender los intereses de la república y del Estado "para cuya conservación están obligados todos los que alienten en sus corazones sangre de verdaderos ciudadanos de una República verdaderamente libre". ${ }^{42}$ A pesar de que en un inicio ser miembro de la Guardia Nacional respondía a un acto de voluntariado, pronto fue obligación inscribirse en ella. ${ }^{43}$

Cervantes y Florencio Quijano por violación de la garantía que les otorga el artículo 5 de la Constitución General en la disposición del Coronel José María Echavarría la remitió de servicio para la colonia militar de Iturbide, 1881, cCJC, Amparo, caja 45, exp. 35; Juicio de amparo promovido por Anastacio Farfán y Sebastián May, vecinos de Lerma, contra actos del capitán de la compañía de Guardia Nacional que viola en sus personas las garantías consignadas en los artículos 5 y 16 de la Constitución General, 1880, cCJC, Amparo, caja 45, exp. 40; Juicio de amparo promovido por la consignación forzosa de Gerardo Díaz, Ignacio Guerrero, Blas Alavez, Anastasio Puc, Tomás A. Chan, Joaquín Esquivel, Saturnino González, José María May, Remegio Huchín, Antonio Canché, José de la C. Canul, Marcial Medina, Isidoro Coob, Agustín Canul y José de la Rosa Noh a prestar sus servicios personales en las armas en las colonias militares de Iturbide y de la región de los indios del sur, 1901, cCJC, Amparo, caja 81, exp. 67.

${ }^{41}$ Marcelino Castilla (1845-1893) era propietario de las haciendas Chapin, Chulbac (Chiná), Chulul, Yaxkabakal, también fue coronel del batallón "Libre" de la Guardia Nacional, Gobernador de Campeche (1877-1880) y presidente de la Sociedad para la construcción del ferrocarril Campeche-Calkiní en 1882.

${ }^{42}$ Citando al Coronel José María Echavarría, Juicio de amparo promovido por Feliciano Tun, Faustino Cervantes y Florencio Quijano por violación de la garantía que les otorga el artículo 5 de la Constitución General en la disposición del Coronel José María Echavarría la remitió de servicio para la colonia militar de Iturbide, cCJc, caja 45, exp. 35, 1881, f. 11.

${ }^{43}$ Jesús Solano González, "La Guardia Nacional”, Aída. Ópera Prima de Derecho Administrativo. Revista de la Asociación Internacional de Derecho Administrativo, n. 12 (julio-diciembre 2012): 210. 
A pesar de que la última batalla contra los mayas rebeldes había sucedido en mayo de 1901 en Chan Santa Cruz, las tropas federales seguían presentes en la península, ${ }^{44}$ por lo cual, el gobierno del estado de Campeche seguía ordenando a los jefes políticos mandar ciudadanos con motivo de la campaña emprendida por el gobierno federal para lograr la definitiva pacificación de los mayas rebeldes y por temor a que los "salvajes huyendo de las fuerzas de ocupación invadiesen el territorio del Estado o proveedores de acuerdo con los indios de los cantones de Xkauhá e Icaiché lograsen su levantamiento". ${ }^{45}$ Así, los batallones Sur, Independiente y Unión de la Guardia Nacional siguieron prestando su servicio en los destacamentos establecidos en Iturbide (partido de Hecelchakán) y en el de los Chenes bajo las órdenes del jefe de las fuerzas federales. Las compañías de los dichos batallones eran compuestas por hombres originarios de los pueblos de Hecelchakán, Calkiní, Tenabo, Becal, Dzibalché, Hopelchen, Bolonchen, Sahcabchen, en su mayoría ciudadanos-soldados con apellidos mayas, a excepción de los altos mandos.

Como se dijo más arriba, entre los 63 juicios de amparo, solamente cuatro fueron interpuestos por indígenas para evitar el servicio armado de la Guardia Nacional, y en las cuatro ocasiones el amparo les fue negado. En realidad, en Campeche el uso de este recurso judicial por tal motivo fue escaso porque existía una vía más rápida llamada exceptuación o excepción ${ }^{46}$ en la que el interesado - o un familiar- prefería recurrir mediante un escrito dirigido al gobernador del estado en el que argumentaba las razones que le impedían ser recluta de la Guardia Nacional: por problema de salud, por ser el único sustento de la familia, por ser menor de edad, etcétera. Con

${ }^{44}$ Hasta el 1 de junio de 1904 cuando se declaró terminada la campaña. Diario de Yucatán, POE, 20 de septiembre de 1904.

${ }^{45}$ Carta del Jefe político del partido de Campeche, A. Sotelo al juez de Distrito, 5 de octubre 1901, CCJC, Amparo, caja 81, exp. 67, f. 5. Juicio de amparo promovido por la consignación forzosa de Gerardo Díaz, Ignacio Guerrero, Blas Alavez, Anastasio Puc, Tomás A. Chan, Joaquín Esquivel, Saturnino González, José María May, Remegio Huchín, Antonio Canché, José de la C. Canul, Marcial Medina, Isidoro Coob, Agustín Canul y José de la Rosa Noh a prestar sus servicios personales en las armas en las colonias militares de Iturbide y de la región de los indios del sur, ccJc, Amparo, caja 81, exp. 67, 1901.

46 Tanto el término excepción como exceptuación significa "acción y efecto de exceptuar". En los expedientes consultados aparecen ambas palabras, aunque a menudo "excepción" se usa como substantivo: "La excepción en la Guardia Nacional”, y "exceptuación”, como verbo: "Se exceptúan del servicio de la Guardia Nacional”, o bien como substantivo derivado del participio "los exceptuados". 
motivos suficientemente válidos, el pago de una cuota mensual y la presentación de un fiador, eran exceptuados de la Guardia Nacional.

En Campeche, entre 1875 y 1903, más de 1500 hombres se beneficiaron de esta excepción, ${ }^{47}$ algunos de forma definitiva si demostraban que eran ineptos física o mentalmente ${ }^{48}$ otros porque no cumplían con los tres años mínimos de vecindad, o bien porque habían superado la edad reglamentaria, y otros - que fueron los más numerosos-, mientras podían pagar la cuota fijada a uno o dos pesos, una contribución que permitía, en parte, financiar los gastos de la Guardia Nacional. ${ }^{49}$ Entre 1860 y 1888, con base en las sucesivas leyes reglamentarias, presentar un fiador era una obligación. En un estudio preliminar ponemos en evidencia que muchos hacendados y comerciantes afianzaban o pagaban esta cuota mensual para impedir que su personal masculino se marchara durante meses con los batallones de la Guardia Nacional, con el riesgo de que muriera o que huyera dejando atrás sus deudas.

Así, la diferencia fundamental entre el amparo y la excepción radica en que el primero era una medida legal para los hombres que ya formaban parte del ejército federal, pero que habían sufrido un abuso de autoridad al ser reclutados en contra de su voluntad. Era un juicio que se desarrollaba ante el juez, el promotor fiscal y el escribano dentro de las instalaciones del tribunal, sin costo para los más pobres. La excepción era una petición de un civil dirigida al gobernador a través de la Secretaría de Guerra y la Guardia Nacional del Estado para evitar formar parte de los batallones de la Guardia Nacional. Mucho más rápido que interponer un amparo - la respuesta tardaba entre dos y tres días- sin necesidad de traer testigos.

Consideraciones finales

En el Tribunal de Campeche, entre 1875 y 1903, una parte ínfima de los soldados que constituían el ejército federal recurrieron al juicio de amparo

${ }^{47}$ Los expedientes de excepción se ubican en el Archivo General del Estado de Campeche (AGEC), Gobernación, Sección: Militar, Serie Exceptuación. El primer caso registrado en Campeche tiene fecha de 1860 y el último de 1909.

${ }^{48}$ En la carta se adjuntaban dos certificados médicos (en los primeros años fueron médicos particulares, después era necesario que formaran parte de la junta calificadora) como medio de comprobación de la enfermedad.

${ }^{49}$ El ayuntamiento mediante nuevos arbitrios y las contribuciones de los exceptuados financiaba la Guardia Nacional. Alicia Hernández Chávez, Las fuerzas armadas mexicanas. Su función en el montaje de la República (México: El Colegio de México, 2012), 48. 
porque habían decidido deliberadamente no prestarse al servicio de las armas y porque consideraban que habían sido violadas sus libertades. Durante más de veinticinco años 96 individuos tuvieron el valor (o la cobardía, según el ángulo de quien lo vea) de no querer servir a la nación armas en mano e involucrarse en una guerra contra indígenas sublevados que no les correspondía. En este trabajo los juicios de amparo constituyeron una sólida fuente para el estudio de la sociedad masculina dentro del ejército y nos permiten reafirmar que los soldados de leva provenían del mundo rural, eran principalmente jornaleros y labradores, de modo que su ausencia ocasionaba un consecuente trastorno económico para sus familias que quedaban huérfanas del sustento pecuniario. Analfabetas y poco instruidos, desconocían quizás la existencia o las facilidades de solicitar un amparo, de allí que el número total de juicios fue bajo comparado con los miles de efectivos que conformaron las tropas federales. Total desconocimiento de la ley, miedo a denunciar, quizás la práctica de la leva haya sido sobrevalorada en la historiografía de la segunda mitad del siglo xIX. Al personalizar a estos hombres, se evidencia que la Guerra de Castas no fue una confrontación de mayas rebeldes contra soldados con alto valor patriótico, motivados por el odio y en pro de la civilización, cuando la mayoría no sabían ni leer, ni escribir y ni deseaban usar las armas dentro de un ejército plurirregional. Su participación activa fue un acto de sobrevivencia de lo más primitivo: matar o ser matado. El constante uso de la fuerza popular en el estado de Campeche en complemento con el refuerzo del ejército federal durante y después de la Guerra de Castas es un campo fértil para futuras investigaciones. Así, la convergencia de datos, sometidos a un rigoroso tratamiento cuantitativo, entre recursos de amparo y exceptuados de la Guardia Nacional podría afinar el conocimiento respecto al desuso de la leva reemplazada por la obligatoriedad de servir en la Guardia Nacional.

\section{FUENTES}

Archivos

Archivo del Ministerio de Asuntos Extranjeros (amaE), Courneuve, Francia. Archivo General del Estado de Campeche (aGEC), Campeche, México. Casa de la Cultura Jurídica de Campeche (ссJc), Campeche, México. 


\section{Hemerografía}

Boletín de la 4a. División Militar, 22 de julio de 1869.

El Cosmopolita, 16 de diciembre de 1837; 2 de junio de 1838; 26 de septiembre de 1838; 8 de diciembre de 1838; 23 de enero de 1839; 26 de marzo de 1842.

Diario de Yucatán, POE, 20 de septiembre de 1904.

Siglo Diez y Nueve, 10 de diciembre de 1861; 28 de enero de 1869; 29 de diciembre de 1882.

Bibliografía

Arroyo Moreno, Jesús Ángel. “El origen del juicio de amparo." En La génesis de los derechos humanos en México, coordinación de Margarita Moreno-Bonett y María del Refugio González Domínguez, 43-61. México: Universidad Nacional Autónoma de México, Instituto de Investigaciones Jurídicas, 2006.

Ceja Andrade, Claudia. "Amanecer paisanos, dormir soldados... El reclutamiento forzoso en la ciudad de México, 1824-1858.” Estudios de Historia Moderna y Contemporánea de México, n. 55 (2018): 3-40. http://dx.doi.org/10.22201/iih. 24485004e.2018.55.63296.

Colección de las sentencias pronunciadas por los tribunales federales de la República. V. 2. México: Imprenta de Francisco Díaz de León, Segunda época, 1882.

Dumond, Don Edmond. El machete y la cruz. México: Universidad Nacional Autónoma de México/Plumsock Mesoamerican Studies/Maya Educational Foundation, 2005.

García Ramírez, Sergio. "El Ministerio Público.” En El Ministerio Público en el Distrito Federal. México: Universidad Nacional Autónoma de México, Instituto de Investigaciones Jurídicas/Procuraduría Federal de Justicia, 1997.

Héau-Lambert, Catherine y Enrique Rajchenberg. "La identidad nacional. Entre la patria y la nación: México, siglo xix." Cultura y Representaciones Sociales 2, n. 4 (2008): 42-71.

Hernández Chávez, Alicia. Las fuerzas armadas mexicanas. Su función en el montaje de la República. México: El Colegio de México, 2012.

James, Thimothy M. "Illegal Military Recruitment and Constitutional Law: The Judicial Protection of Forced Recruits in Late Nineteenth-Century Mexico." The America 76, n. 3 (2019): 415-442. https://doi.org/10.1017/tam.2019.32. Martin, Norma. "Pobres, mendigos y vagabundos en la Nueva España, 1702-1766." Estudios de Historia Novohispana, n. 3 (1985): 99-126. http://dx.doi.org/ 10.22201/iih.24486922e.1985.008.3285. 
Martínez González, Xochitl. "La enseñanza primaria e instrucción del soldado del ejército permanente mexicano en la primera mitad del siglo xIx." Tiempo y Espacio, n. 64 (julio-diciembre 2015): 331-350.

Palomino Manchego, José F. "La primera sentencia de amparo en México (Un antecedente de historia constitucional)." En El juicio de amparo a 160 años de la primera sentencia, coordinación de Manuel González Oropeza y Eduardo Ferrer Mac-Gregor, 335-343. México: Universidad Nacional Autónoma de México, 2011.

Pérez Toledo, Sonia. "Los vagos de la ciudad de México y el Tribunal de Vagos en la primera mitad del siglo xIx.” Secuencia, n. 27 (1993): 27-42. http://dx.doi. org/10.18234/secuencia.v0i27.436.

Ramírez Rancaño, Mario. "Ejército federal, jefes políticos, amparos, deserciones: 1872-1914.” Estudios de Historia Moderna y Contemporánea de México, n. 47 (enero-junio 2014): 41-48. http://dx.doi.org/10.1016/S0185-2620(14)70334-2. Ramírez Rancaño, Mario. La justicia durante el Porfiriato y la Revolución, 1898-1914. Los amparos entre el ejército federal. México: Suprema Corte de Justicia de la Nación, 2010.

Ramírez Reyes, José Daniel (2015). "Preparando a las Fuerzas armadas para un enfrentamiento inminente. La organización del Ejército mexicano de 1839.” En Memoria del 1er. Congreso Nacional de Historia Militar de México a través de los Archivos Históricos. V. 1, 317-326. México: Secretaría de la Defensa Nacional, Dirección General de Archivo e Historia, 2015.

Rodríguez de S. Miguel, Juan M. Pandectas hispano-megicanas o sea Código general comprensivo de las leyes generales, útiles y vías. V. 2. México: Impreso en la oficina de Mariano Galván Rivera, 1840.

Serrano Ortega, José Antonio. El contingente de sangre. El reclutamiento del ejército permanente mexicano, 1824-1846. México: Instituto Nacional de Antropología e Historia, 1993.

Serrano Ortega, José Antonio. "Levas, Tribunal de Vagos y Ayuntamiento: la ciudad de México, 1825-1836." En La experiencia institucional en la ciudad de México. 1821-1929, edición de Carlos Illades y Ariel Rodríguez Kuri, 131-154. México: Universidad Autónoma Metropolitana-Iztapalapa/El Colegio de Michoacán, 1996.

Soberanes Fernández, José Luis. "Surgimiento del amparo judicial.” En El juicio de amparo a 160 años de la primera sentencia, coordinación de Manuel González Oropeza y Eduardo Ferrer Mac-Gregor, 465-484. México: Universidad Nacional Autónoma de México, 2011. 
Solano González, Jesús. "La Guardia Nacional.” Aída. Ópera Prima de Derecho Administrativo. Revista de la Asociación Internacional de Derecho Administrativo, n. 12 (julio-diciembre 2012): 207-240.

Torras Conangla, Rosa. Colonización y colonialidad en una selva de frontera. La Cuenca campechana del río Candelaria (siglos XIX y XX). Mérida: Universidad Nacional Autónoma de México, Centro Peninsular en Humanidades y Ciencias Sociales, 2019.

Torras Conangla, Rosa. La tierra firme de enfrente: la colonización campechana sobre la región de Los Ríos ( siglo XIX). Mérida: Universidad Nacional Autónoma de México, Centro Peninsular en Humanidades y Ciencias Sociales, 2012.

Valls Hernández, Sergio. "El juicio de amparo a 160 años de la primera sentencia." En El juicio de amparo a 160 años de la primera sentencia, coordinación de Manuel González Oropeza y Eduardo Ferrer Mac-Gregor, 525-539. México: Universidad Nacional Autónoma de México, 2011.

\section{SOBRE LA AUTORA}

Doctora en Études sur l'Amérique Latine por la Universidad de Toulouse (Francia), está adscrita al Centro de Investigaciones Históricas y Sociales de la Universidad Autónoma de Campeche desde el 2009. Es miembro del Sistema Nacional de Investigadores. Entre sus últimas publicaciones se encuentran "Una medalla militar por matar mayas rebeldes", Estudios de Cultura Maya, n. 50, 2017; y "Le Yucatan dans les lettres consulaires de la France à Campêche (1832-1850)”, Nuevo Mundo Mundos Nuevos (2018). 
